\title{
Comparison of Macintosh, McCoy and Miller Laryngoscope Blades for Intubation- A Prospective Randomised Study
}

\author{
Dr. Manali Nadkarni ${ }^{1}$, Dr. R. D. Patel ${ }^{2}$, Dr. Prashant Behera ${ }^{3}$, \\ Dr. Atul Walzade ${ }^{4}$ \\ ${ }^{I}$ (Additional Professor, Department Of Anaesthesiology/Seth G.S.Medical College \& K.E.M. Hospital, India) \\ ${ }_{2}^{2}$ (Professor, Department Of Anaesthesiology/Seth G.S. Medical College \& K.E.M. Hospital, India) \\ ${ }_{3}^{3}$ (Ex Postgraduate Student, Department Of Anaesthesiology/Seth G.S. Medical College \& K.E.M. Hospital, India) \\ ${ }^{4}$ (Assistant Professor, Department Of Anaesthesiology/Seth G.S.Medical College\& K.E.M. Hospital, India)
}

\begin{abstract}
Maintenance of airway during anaesthesia is very important to anaesthesiologist. A prospective, randomized study was conducted in 300 patients posted for various surgeries under general anaesthesia with endotracheal intubation to evaluate differences in glottic view, attempts of laryngoscopy and intubation attempts associated with the three blades- Macintosh, McCoy and Miller laryngoscope blade. They were allocated in three groups. In first group laryngoscopy was done with Macintosh blade, in second group with McCoy blade, in third group with Miller blade. In this study it was found that Cormack LehaneGrade III view was more with Macintosh and McCoy blade which was more in comparison to Miller blade. Degree of difficulty in intubation was more with Miller blade in comparison to Macintosh and McCoy blade which is statistically significant ( $p$ value $<0.05$ ).
\end{abstract}

Keywords: Cormack Lehane Grade, Degree of difficulty in intubation, Macintosh blade, McCoy blade, Miller blade

\section{Introduction}

The anaesthesiologists play a very important role in health care, rendering patient free from pain either in the form of regional anaesthesia or general anaesthesia to facilitate surgical procedure.As such, the primary responsibility of the anaesthesiologist as a clinician is to safeguard the airway i.e. to preserve and protect it during induction, maintenance and recovery from the state of anaesthesia and in the event of loss of the airway, it should be promptly re-established before the individuals suffers irreversible injury from inadequate or compromised oxygenation. Failure to maintain a patent airway for more than a few minutes can lead to hypoxia, hypercarbia, metabolic alterations, brain damage or death. And it has been estimated that inability to successfully manage very difficult airways has been responsible for as many as $30 \%$ of deaths totally attributable to anaesthesia ${ }^{1,2}$. Thus airway is very important from anaesthesia point of view. Various methods have been used to secure an airway e.g. orotracheal, nasotracheal and tracheostomy. There are many studies comparing different types of laryngoscopes in general and in a difficult intubation scenario. Our study is about comparing Macintosh, McCoy and Miller blades regarding their differences in view of the glottis, attempts of laryngoscopy, intubation attempts and complications associated with the individual blade.

\section{Methods}

A randomized study was conducted prospectively consisting of 300 adult patients posted for surgical procedure under general anaesthesia. After the Institutional Ethics Committee approval patients were divided into 3 groups of 100 each randomly. In first group(group A) direct laryngoscopy was done with Macintosh laryngoscope blade $^{3}$, in second group(group B) with McCoy laryngoscope blade ${ }^{3}$, in third group (group C) with Miller laryngoscope blade ${ }^{3}$. Patients included were patients with ASA grade I and II, mouth opening $>3.5 \mathrm{~cm}$, neck movements normal, and requiring general anaesthesia. Patients excluded were patients with cervical spine abnormalities, oral cavitytumor or abscess and those with any abnormality of the airway. Airway assessment was done clinically by Mallampati classification ${ }^{4}$ (MPC) for oropharyngeal view. Along with routine general and systemic examination, thorough airway assessment ${ }^{5,6,7}$ was carried out. It included inter-incisor gap, MPCgrading, temporomandibular joint mobility, neck extension, mandibular space, thyromental distance, mentosternal distance and condition of teeth i.e. loose, missing, artificial or bucked teeth.

The patients were premedicated. Preoxygenation with 100\% oxygen was done for 5 minutes and patients sedated with Inj. Midazolam $0.03 \mathrm{mg} / \mathrm{kg}$ iv and Inj.Pentazocine $0.3 \mathrm{mg} / \mathrm{kg}$ iv 5 minutes prior to induction of anaesthesia. Induction was done using Inj. Propofol $2 \mathrm{mg} / \mathrm{kg}$ iv After confirming adequate mask ventilation, neuromuscular blocking agent, Inj. Vecuronium $0.1 \mathrm{mg} / \mathrm{kg}$ iv was given. After mask ventilation with nitrous oxide and oxygen (60:40) for 3 minutes and oxygen 100\% for one minute, position for laryngoscopy was given. 
Laryngoscopy was done with either Macintosh, McCoy or Miller laryngoscope blade by an experienced anaesthesiologist.

After successful endotracheal intubation, the tube was attached to the circuit, patient ventilated with $100 \%$ oxygen. Tube position confirmed with auscultation of chest, end tidal carbon dioxide, maintenance of oxygen saturation, pulse rate, blood pressure. Endotracheal tube fixed at appropriate mark. Complications like trauma to lips, trauma to pharynx, tooth fall, tooth loosening, secretions, laryngospasm, bronchospasm, desaturation, oesophageal intubation were noted and recorded.

\section{Cormack Lehane Grades of Laryngoscopic View}

Laryngoscopic view was graded according to Cormack and Lehane ${ }^{8,9}$ classification.

Grade I: Full glottic exposure.

Grade II:Only posterior portion of glottis seen.

Grade III:Only epiglottis seen, no glottic exposure.

Grade IV:Not even the epiglottis can be seen.

\section{Degree Of Difficulty In Intubation}

Degree of difficulty in intubation is graded as

Grade -I:Intubation easy

Grade -II: Intubation requiring an increased anterior lifting force and assistance to pull the right corner of the mouth upwards to augment space.

Grade -III:Intubation requiring multiple attempts and a curved stylet.

Grade -IV: Failure to intubate with the assigned laryngoscope blade

The Degree of difficulty in intubation grade III and IV are predictors of difficulty in maneuvering of the tube during intubation.Our main interest was to compare the ease of viewing the glottis between the Macintosh, McCoy and Miller laryngoscope blades and ease of intubation. The statistical analysis of the study was carried out by GraphPadInstat. ANOVA application, Chi square test, students t test wherever applicable.

\section{Results}

Patients were comparable to each other regarding demographic characteristics like age, weight, sex, ASA status. Patients were also comparable regarding airway assessment like mouth opening, mandibular space, atlantoaxial joint extension, Mallampatti classification.

Table-1

Demography Characteristics

\begin{tabular}{|c|c|c|c|}
\hline Parameters & $\begin{array}{l}\text { Group A } \\
\text { (Macintosh) }\end{array}$ & $\begin{array}{l}\text { Group B } \\
\text { (Mc } \\
\text { blade) }\end{array}$ & $\begin{array}{l}\text { Group C } \\
\text { (Miller blade) }\end{array}$ \\
\hline No. of Patients & 100 & 100 & 100 \\
\hline $\begin{array}{c}\text { Age (yrs) } \\
\text { Mean }\end{array}$ & 33.60 & 33.02 & 31.06 \\
\hline $\begin{array}{l}\text { SD } \\
\text { Range }\end{array}$ & $\begin{array}{l}10.93 \\
18-59 \text { yrs }\end{array}$ & $\begin{array}{l}9.68 \\
18-55 \text { yrs }\end{array}$ & $\begin{array}{l}10.16 \\
18-59 \text { yrs }\end{array}$ \\
\hline $\begin{array}{l}\text { Weight (kgs) } \\
\quad \text { Mean } \\
\text { SD } \\
\text { Range }\end{array}$ & $\begin{array}{l}56.61 \\
7.98 \\
37-82 \mathrm{kgs}\end{array}$ & $\begin{array}{l}55.82 \\
6.56 \\
40-70 \mathrm{kgs}\end{array}$ & $\begin{array}{l}53.72 \\
6.65 \\
35-69 \mathrm{kgs}\end{array}$ \\
\hline $\begin{array}{l}\text { Sex }(\%) \quad \text { Male } \\
\text { Female }\end{array}$ & $\begin{array}{l}54(54.0) \\
46(46.0)\end{array}$ & $\begin{array}{l}53(53.0) \\
47(47.0)\end{array}$ & $\begin{array}{l}50(50.0) \\
50(50.0)\end{array}$ \\
\hline $\begin{array}{l}\text { ASA Grade(\%) } \\
\text { I } \\
\text { II }\end{array}$ & $\begin{array}{l}87(87.0) \\
13(13.0)\end{array}$ & $\begin{array}{l}87(87.0) \\
13(13.0)\end{array}$ & $\begin{array}{l}86(86.0) \\
14(14.0)\end{array}$ \\
\hline
\end{tabular}

By Chi-Square test $\mathrm{P}>0.05$ Not Significant 
Table -2

Comparison Of Cormack Lehane Grading Between The Groups

\begin{tabular}{|c|c|c|c|}
\hline & $\begin{array}{l}\text { Group A } \\
\text { (Macintosh) } \\
(\mathbf{N}=100) \\
\text { No. } \%\end{array}$ & $\begin{array}{l}\text { Group B } \\
\text { (Mc Coy blade) } \\
(\mathrm{N}=100) \\
\text { No. } \%\end{array}$ & $\begin{array}{l}\text { Group C } \\
\text { (Miller blade) } \\
(\mathbf{N}=100) \\
\text { No. } \%\end{array}$ \\
\hline I & *78 & 88.0 & 97.0 \\
\hline II & 18 & 10.0 & 03.0 \\
\hline III & *04 & 02.0 & - \\
\hline
\end{tabular}

By Chi - Square Test

$* \mathrm{P}<0.05$ Significant

Table 2shows thatas per Cormack Lehane grading 78.0\% of the cases from Group A were graded as Grade I which was significantly low as compared to $88.0 \%$ among Group B and $97.0 \%$ in Group C. $4.0 \%$ of the total cases from Group A were graded as grade III which was significantly more as compared to not a single patient among Group C and $2.0 \%$ in Group B which was not significant with other two groups.

Table-3

Comparison of use of stylet between the groups

\begin{tabular}{|c|c|c|c|c|c|c|}
\hline \multirow[t]{2}{*}{ Stylet } & \multicolumn{2}{|c|}{$\begin{array}{l}\text { Group A } \\
\text { (Macintosh) } \\
(\mathbf{N}=\mathbf{1 0 0})\end{array}$} & \multicolumn{2}{|c|}{$\begin{array}{l}\text { Group B } \\
\text { (Mc Coy blade) } \\
(\mathbf{N}=\mathbf{1 0 0})\end{array}$} & \multicolumn{2}{|c|}{$\begin{array}{l}\text { Group C } \\
\text { (Miller blade) } \\
(\mathrm{N}=100)\end{array}$} \\
\hline & No. & $\%$ & No. & $\%$ & No. & $\%$ \\
\hline Yes & $* 22$ & 22.0 & $* 19$ & 19.0 & $* 58$ & 58.0 \\
\hline No & 78 & 78.0 & 81 & 81.0 & 42 & 42.0 \\
\hline
\end{tabular}

ByChi - Square Test $* \mathrm{P}<0.05$ Significant

Table 3 shows that $58.0 \%$ of the cases of group $\mathrm{C}$ had mean stylet use which was significantly more as compared to $19.0 \%$ among Group B and $22.0 \%$ from Group A 
Table-4

Comparison Of No. Of Attempts Required For Intubation

By Chi - Square Test

\begin{tabular}{|c|c|c|c|c|c|c|}
\hline \multirow[t]{2}{*}{ No. of Attempts } & \multicolumn{2}{|c|}{$\begin{array}{l}\text { Group A } \\
\text { (Macintosh) } \\
(\mathrm{N}=100)\end{array}$} & \multicolumn{2}{|c|}{$\begin{array}{l}\text { Group B } \\
\text { (Mc Coy blade) } \\
(\mathrm{N}=100)\end{array}$} & \multicolumn{2}{|c|}{$\begin{array}{l}\text { Group C } \\
\text { (Miller blade) } \\
(\mathrm{N}=100)\end{array}$} \\
\hline & No. & $\%$ & No. & $\%$ & No. & $\%$ \\
\hline 1 & 80 & 80.0 & $* 88$ & 88.0 & $* 72$ & 72.0 \\
\hline 2 & 18 & 18.0 & 12 & 12.0 & 24 & 24.0 \\
\hline 3 & 02 & 02.0 & - & - & $* 04$ & 04.0 \\
\hline
\end{tabular}

Table 4 shows that $72.0 \%$ of the cases from Group $\mathrm{C}$ required only 1 attempt for intubation which wassignificantly low as compared to $88.0 \%$ among Group B and $80.0 \%$ from Group A which was not significant. $4.0 \%$ of the cases from Group $\mathrm{C}$ required 3 attempts for intubation which was significantly more as compared not a single patient from Group B.

Table-5

Comparison Of Degree Of Difficulty In Intubation BetweenThe Groups

\begin{tabular}{|c|c|c|c|c|}
\hline Degree & $\begin{array}{l}\text { Group A } \\
\text { (Macintosh) } \\
(\mathrm{N}=100)\end{array}$ & $\begin{array}{l}\text { Group B } \\
\text { (Mc Coy blade) } \\
(\mathrm{N}=100)\end{array}$ & \multicolumn{2}{|c|}{$\begin{array}{l}\text { Group C } \\
\text { (Miller blade) } \\
(\mathrm{N}=100)\end{array}$} \\
\hline 1 & 85.0 & 86.0 & 78 & 78.0 \\
\hline 2 & $08 \quad 08.0$ & 09.0 & 06 & 06.0 \\
\hline 3 & 07 & 05 & $* 16$ & 16.0 \\
\hline
\end{tabular}

By Chi - Square Test

$* \mathrm{P}<0.05$ Significant

Table 5shows in this study group $78.0 \%$ of the total cases from Group $\mathrm{C}$ had one degree difficulty in intubation which was low as compared to $85.0 \%$ among Group A and $86.0 \%$ in Group B but difference was not statistically significant. $16.0 \%$ of the cases from $\mathrm{C}$ had a third degree of difficulty in intubation which was significantly more as compared to $7.0 \%$ among Group A and 5.0\% among Group B. 


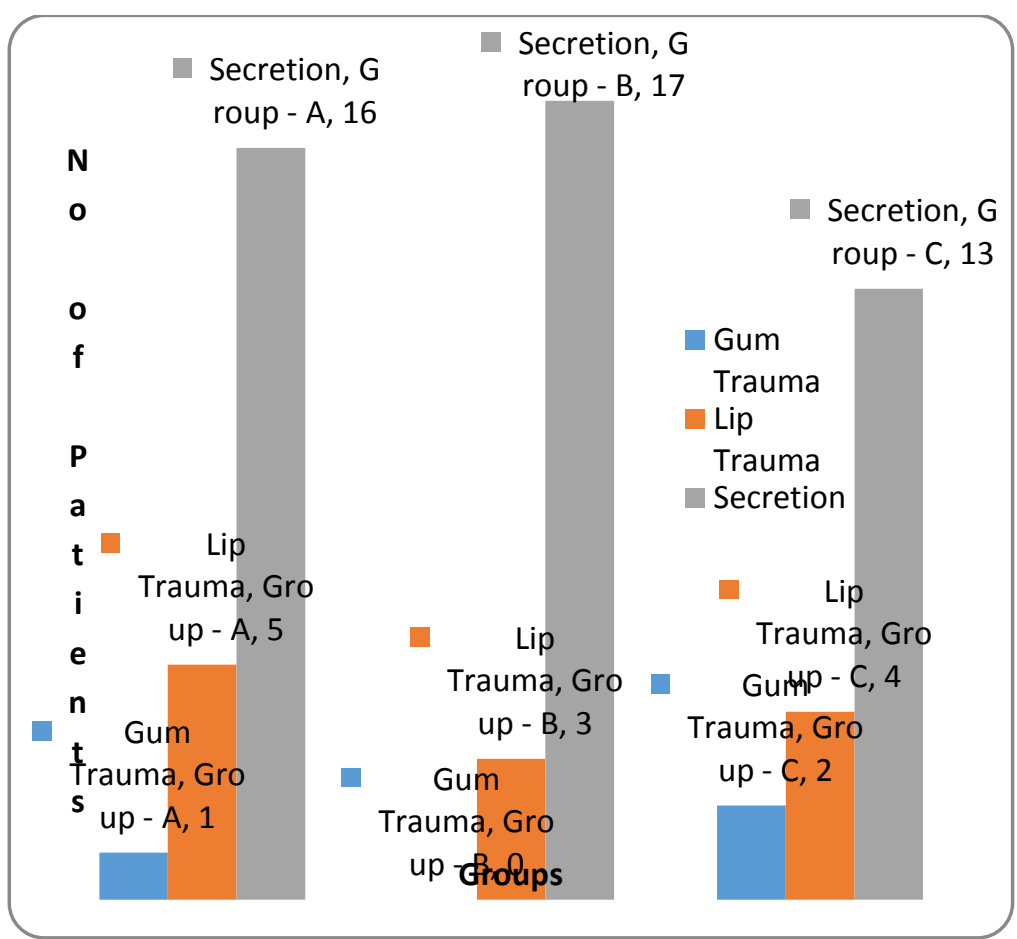

\section{Graph-Comparison of complications}

\section{Discussion}

An American Society of Anesthesiologists close claim analysis of adverse outcomes associated with anaesthesia showed that the most common cause of serious injury was due to inadequate ventilation (38\%), oesophageal intubation (18\%) and difficult tracheal intubation $(17 \%)^{\mathbf{1 , 2}}$.Preoperative airway evaluation of patients would decrease the rate of anaesthesia related adverse respiratory event.Patients were comparable to each other regarding demographic characteristics like age,

weight, sex, ASA status. Patients were also comparable regarding airway assessment like mouth opening, mandibular space, atlantoaxial joint extension, mallampatti classification.

In this study group laryngoscopic view as per Cormack Lehane grading $78.0 \%$ of the cases from Group A were graded as Grade I which was significantly low as compared to $88.0 \%$ among Group B and $97.0 \%$ in Group C. $4.0 \%$ of the total cases from Group A were graded as grade III which was significantly more as compared to not a single patient among Group C and 2.0\% in Group B which was not significant with other two groups. In the study byArino J. J.et $\mathbf{~ a l}{ }^{10}$ laryngoscopic views obtained Belscope and Miller blades were similar and better than with the other type of laryngoscopes. $(p<0.001)$. The levering tip of the McCoy blade $(p=0.02)$ significantly improves the laryngoscopic view.

In cases of difficult tracheal intubation a good view can be achieved using the Miller blade lateral to the tongue (paraglossal technique), which enabled tracheal intubation under direct vision. The improved view obtained with this technique is a consequence of reduced tongue compression as compared with the Macintosh blade. This leads both to an improved line of sight, and to a reduced risk of backward displacement of the tongue and epiglottis. Thus paraglossal straight blade laryngoscopy may have an advantage over use of the Macintosh technique when intubation proves unexpectedly difficult ${ }^{11}$.

$58.0 \%$ of the cases of group $\mathrm{C}$ had mean stylet use which was significantly more as compared to $19.0 \%$ among Group B and $22.0 \%$ from Group A.In this study group, $72.0 \%$ of the cases from Group C required only 1 attempt for intubation which was significantly low as compared to $88.0 \%$ among Group B and $80.0 \%$ from Group A which was not significant. $4.0 \%$ of the cases from Group C required 3 attempts for intubation which was significantly more as compared not a single patient from Group B.

In this study group, $78.0 \%$ of the total cases from Group A had one degree difficulty in intubation which was low as compared to $85.0 \%$ among Group B and $86.0 \%$ in Group C but difference was not statistically significant.16.0\% of the cases from Group $\mathrm{C}$ had a third degree of difficulty in intubation which was significantly more as compared to $7.0 \%$ among Group A and 5.0\% among Group B. In the study by Arino J.J. et $\mathbf{a l}^{10}$ ease of intubation with Macintosh and McCoy blades were similar and was highest $(\mathrm{p}<0.001)$. Curved blades provide more room in the oropharynx to maneuver the endotracheal tube. Better results were obtained with the Miller blade than with the Belscope and Lee- Fiberview blade $(p<0.001)$. Curved tip of the Miller 
blade helps to obtain better intubating conditions than other straight blades because it increases the exposure of the vocal cords and the room in which to maneuver the endotracheal tubes. In the study done byB.Achen, O.C.Terblancheet $\mathbf{~ a l ~}^{\mathbf{1 2}}$ intubating condition were similar with the Macintosh and Miller blade .This may be due to their use ofparaglossal approach ${ }^{11}$.

In the present study $72.0 \%$ of the cases from Group $\mathrm{C}$ required only 1 attempt for intubation which was significantly low as compared to $88.0 \%$ among Group B and 80.0 from Group A which was not significant. $4.0 \%$ of the cases from Group $\mathrm{C}$ required 3 attempts for intubation which was significantly more as compared not a single patient from Group B. In between the attempts patient was ventilated with $100 \%$ oxygen .In two cases where the glottic view with the Macintosh blade is grade III the intubation had to be aided with some maneuvers (BURP), a device like bougie or a smaller number endotracheal tube.

Mean time required was 34.10 among group A which was more as compared to 33.94 in group B and 32.16 among group $\mathrm{C}$ but difference was not statistically significant.

In this study group $16.0 \%$ of the total cases from Group A and $17.0 \%$ of the total cases from B had a complication of secretion which was more as compared to $13.0 \%$ among Group $\mathrm{C}$ but difference was not statistically significant. $5.0 \%$ of the total cases from Group A and $4.0 \%$ of the total cases from Group C had a lip trauma which was more as compared to $3.0 \%$ among Group B but not statistically significant

\section{V.Conclusion}

From our study we found that there was clinically significant difference in the Cormack Lehane Grade between the three blades. Miller blade gave best Cormack Lehane Grade, McCoy blade gave good Cormack Lehane Grade, Macintosh blade gave good Cormack Lehane Grade. Miller blade is used in difficult intubation cases with narrow mouth opening. Time taken for laryngoscopy is comparable in all the groups. Number of attempts required for intubation is more in Miller group in comparison to other two groups. With regard to degree of difficulty in intubation McCoy and Macintosh blade is better in comparison to Miller blade.

\section{References}

[1]. [1].Caplan R.A., Posner K.L., Ward R.J., Cheney F.W., Adverse respiratory events in anesthesia: a closed claims analysis. Anesthesiology, 72(5), 1990 May, 828-833.

[2]. Cheney FW, Posner KL, Caplan RA. Adverse respiratory events infrequently leading to malpractice suits. A closed claims analysis. Anesthesiology, 75(6), 1991 Dec, 932-939.

[3]. Dorsh JA, Dorsh SE. Laryngoscopes. In: Understanding Anaesthesia Equipment, 4th edn. Baltimore: Williams \& Wilkins, 1998: 505-56.

[4]. Mallampati S.R., Gatt S.P., Gugino L.D., Waraksa B., Freiburger D., Liu P.L., A Clinical sign to predict difficult intubation; A prospective study. Can AnaesthSoc Journal, 32,1985, 429-434.

[5]. Patil V.U., Stehling L.C., Zauder H.L.,Predicting the difficulty of intubation utilizing an intubation guide,AnaesthesiologyReview, 10, 1983, 32-33.

[6]. Savva D. Prediction of difficult tracheal intubation, British Journal ofAnaesthesia ,73, 1994, 149-153.

[7]. Banister FB, Mc Beth RG. Direct laryngoscopy and tracheal intubation, Lancet, 2,1944,651-654.

[8]. Thomas Gal, Airway management, Ronald D. Miller 6th edition Millers Anaesthesia,Elsevier, USA; 2005 : $1617-1651$.

[9]. Cormack R.S., Lehane J., Difficult intubation in obstretics, Anaesthesia, 39(11),1984,1105-1111.

[10]. Arino J.J., Velasco J.M., Gasco C., Lopez-Timoneda F., 'Straight blades improve visualization of the larynx while curved blades increase ease of intubation: a comparison of the Macintosh, Miller, McCoy, Belscope and Lee-Fiberview blades',Canadian Journal of Anesthesia,50, 2003,501-506.

[11]. J.J.Henderson, The use of paraglossal straight blade laryngoscopy in difficult tracheal intubation, Anaesthesia ,52, 1997, 552560.

[12]. B.Achen, O.C.Terblanche, B.T.Finucane, View of the larynx obtained using the Miller blade and paraglossal approach, compared to that with the Macintosh blade,Anaesthesia Intensive Care, 36, 2008, 717 - 721

\section{PHOTO - 1(MACINTOSH BLADE)}

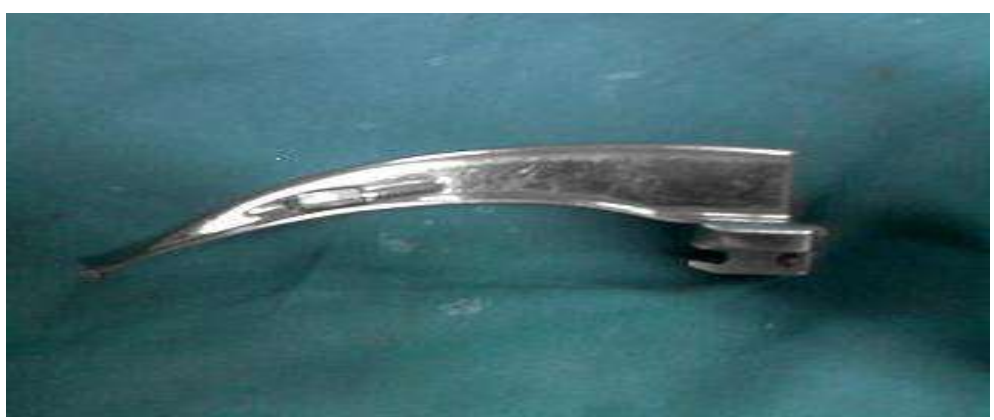


PHOTO -2(MILLER BLADE)

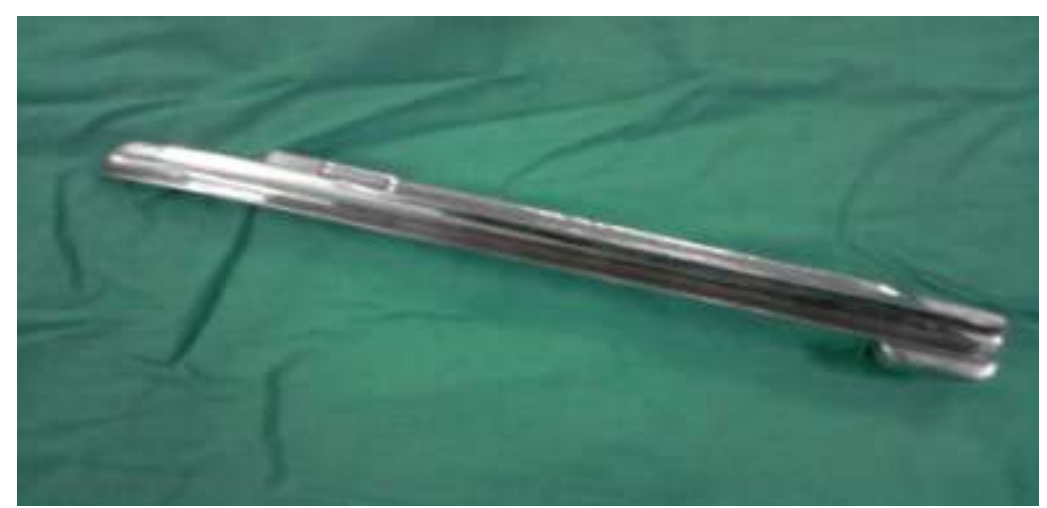

PHOTO - 3(MCCOY BLADE)

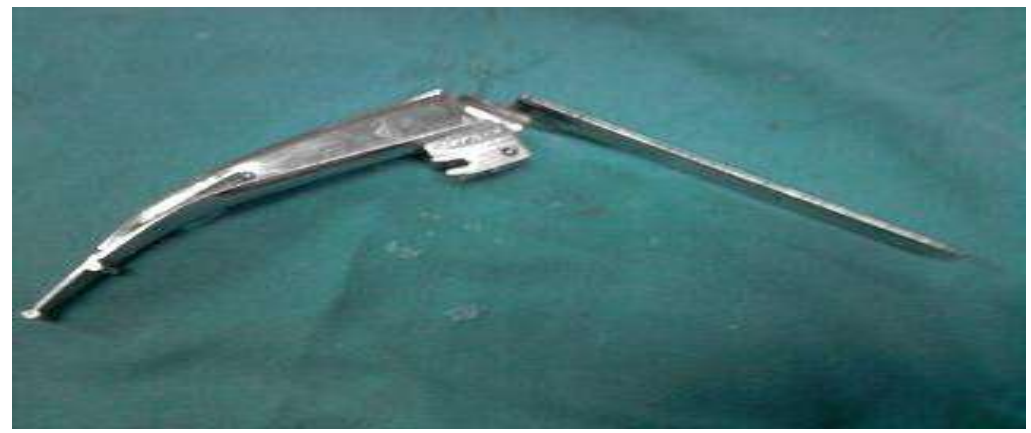

